\title{
RETHINKING PARTICIPATORY PROCESS IN HERITAGE CONSERVATION: SITUATING PROFESSIONALS IN THE PROCESS
}

\author{
Neel Kamal Chapagain
}

Associate Lecturer

University of Wisconsin-Stevens Point, USA

\begin{abstract}
Participatory approach has been used in conservation of historic built environments as a methodological response to the need of including voices from users and inhabitants. However the implication and efficiency of such processes have not always been satisfactory. Drawing from some observations in Nepal, the paper examines the notion of participation in conservation projects and argues that the notion of participation shall be understood from multiple positions. The paper argues that participation is not just about getting users and inhabitants involved in the process, but it should also be about orienting the professionals in the given social context. Unless a professional realizes his/her own worldview and how it may influence the participatory process in a project, the essence of the participation remains in question. As an attempt to address such challenges, this paper draws some theoretical and methodological concepts from anthropology.

Key words: Heritage conservation, Participation, Professional attitudes, Self-reflexivity, Situated perspective
\end{abstract}

\section{Introduction}

As the scope of conservation expands from a mere monument conservation to include larger, lessmonumental but historic and traditional built environments, the underlying approaches too need to be expanded to be inclusive of voices and expectations from a larger group of people. Participatory approach has been advocated and adopted as a methodological response to the call for including users and inhabitants in (re)design and conservation process. Participatory approaches allow users and inhabitants to voice their concerns and expectations as well as to participate in the projects of conservation (vis-a-vis development) directly or indirectly. However there is no definite mantra for a participatory process and in many cases, the processes and results of such participatory processes have not been so efficient. Often the participation of non-professional community remains in the periphery and is limited as a tool for the professionals to interpret their goals. Even with

*Corresponding author: Neel Kamal Chapagain

University of Wisconsin-Stevens Point, USA

Contact:

Email: chapaga2@uwm.edu; neelkamal.chapagain@uwsp.edu (Received: 2011 Sep 01 Accepted:2011Nov 14) best intention, the process of participation suffers from a challenge to bridge the gap between the professionals' vision and the local community's expectations. The examples drawn from the cases in Bhaktapur and Upper Mustang in Nepal elaborate some of the challenges with participatory approach in two different temporal, geographic and social contexts. Drawing from the author's personal experience and integrating them with some theory and methodological approach from anthropology, this paper suggests that the professional community needs to (re)situate themselves in the power relationship in any participatory process.

\section{Lessons from Bhaktapur}

In 1970s, the Government of Nepal with financial and technical assistance from the German Government, decided to launch a comprehensive project to revitalize historic town of Bhaktapur which was gradually losing its historic character while lagging behind in developing other contemporary infrastructures as well. Therefore, the Bhaktapur Development Project (BDP) started with the mission of conserving historic buildings and squares of the old town along with improvement of 
urban infrastructures such as sanitation, street pavements etc. The first goal of the project was to conserve the historic setting while the second goal was to provide adequate urban infrastructures in an old town. The second goal acted as a tool to make community interested in the project mission because they could see a direct connection to some concerns of their daily lives, and thus to support the first goal. In its basic premises, the BDP had a good scope to be a participatory project because conservation goals were tied in with people's everyday life and wellbeing. However, the implementation of the improvements would require the project to cross the boundary from public monuments to private buildings. Y.K. Parajuli, a Nepali architect who was the main Nepali counterpart in the project, noted:

\begin{abstract}
"the planners were aware that their efforts to maintain the urban character, they could not avoid encroaching upon the house - or property - owner's "freedom to construct". The restrictions brought about by zoning and development regulations were bound to be perceived as "imposed" or "authoritarian", especially by a community which has historically and culturally remained outside the influence of "national" institutions and administration.” (Parajuli, 1992)
\end{abstract}

Though the BDP was initially a typical development oriented project guided by professional and institutional values, it differed from other development (as well as conservation) projects by its intent on addressing some of the community concerns. In its successive phases, it attempted to address some socio-economic components into an otherwise core physical development project. One evident example was that the efforts of retaining historic and traditional features of buildings were carried out by providing incentives to the homeowners. For example, a home-owner while seeing improvements to his adjacent streets and other services would also be required to restore his traditional façade and elements like windows and so on. The project would provide financial and technical assistance to the homeowners so that the compliance to conservation criteria would not be a burden on the owner. However, this was not widely popular as much as the project planners would have anticipated because the works done were not necessarily seen as valuable and needed by local people. BDP - being "experimental" as per the mandate given by the German international aid programme - then took what Ane Haaland (1982) called "software approach" in the third phase of the project.

A "software approach" was the focus on humane, non-quantifiable aspects where as the "hardware approach" was the physically quantifiable aspects of the project. In integrating these two approaches in BDP, the term "participation" became a key word in the third phase (Haaland, 1982). Even though there were some degrees of participation sought in the first and second phases of the project, it was limited to a few consultative meetings with a few selected officials and that too was not consistent. In the third phase, however, ensuring people's participation meant that it had to bring in several economic, social, educational, health subprojects to the mainstream conservation project. Such a holistic measure became the asset as well as challenge for the BDP [Please see Haaland, 1982 for detail]. The project must be commended for its approach back then in the seventies, and also for its relative success in generating a community level awareness that has been backbone of many success stories Bhaktapur has to its credit now. However, frustration with the nature of the project is evident when Y.K. Parajuli writes:

“ The Bhaktapur Project emphasized a bottomup approach, which incorporated awarenessraising and voluntary participation. That such an approach might not work in communities such as Bhaktapur's, where the traditional social and cultural values were changing, was not realised until it was too late.

The solution might seem overly harsh to some, but there is no denying the fact that strict and rigid regulations should be designed and imposed from the top if the continuity and survival of traditional townscapes of 
Kathmandu are to be guaranteed. The townpeople must be made to accept the zoning and building regulations as they would be of any other civil regulations. They must be persuaded to accept these regulations as an integral part of their duties as citizens. In parallel, the measures must take full account of the genuine aspirations of the residents to benefit from modern facilities.” (Parajuli, 1992)

Parajuli's reaction must be seen in a larger context where political and social changes in national front were under debate and frequent political strikes had influenced the everyday activities of the project as well. The comment also needs to be considered for the fact that it points towards hardship of implementing participatory process - sometimes also perceived as a bottom-up approach. [However, as we discuss later participation may not necessary mean to replace the typical "top-down approach" with a revolutionary "buttom-up approach”.]

As other cities in the Kathmandu valley attempted to follow Bhaktapur's example, the conflict between conservation goal and peoples' expectation became frequent. The historic areas of Patan and Kathmandu still face a tension between building by-laws that require the traditional buildings to comply with historic characters and house-owner's plans to make a contemporary model house. Had the policy makers been considerate about accommodating the desires to "modernize" and sought a middle way between conservation and development, perhaps the tension between the conservation advocates and local residents would have been less. In other words, had the policy making and project developments in such historic areas followed a participatory approach, perhaps the voices and desires of local people would have been acknowledged while formulating such revitalization plan and policies. It is important to keep in mind that historic places have multiple groups of stakeholders including different groups of residents and users as well as professional and government institutions. However, the conflict arises when one particular group leads and often guides the other groups without any negotiation. Such conflict has surfaced in attempts of managing world heritage sites of Kathmandu valley; for example - the government's attempt to demolish houses around Bouddha a few years ago. The government's action came as it was under pressure from UNESCO to take "proper" actions to maintain the integrity of world heritage sites. One noted official from the government's Department of Archaeology even blames UNESCO for not understanding the everyday lives that exist around the World Heritage Sites in Kathmandu valley while exerting pressure on the government to keep with the conservation norms and standards (Shrestha, 2002).

\section{Experiences from Lomanthang, Upper Mustang}

Lomanthang is a small walled settlement in the trans-Himalayan region in Northwest Nepal. It was settled as a secured walled capital city in the $15^{\text {th }}$ century for then Kingdom of Lo which in the $18^{\text {th }}$ century became part of contemporary Nepal. Being originally part of a Tibetan Kingdom, Lomanthang at present is like a cultural capital for people of Tibetan Buddhism culture. The author worked in a cultural heritage conservation project in Lomanthang, that restored some centuries old Buddhist Gompas. The project's mission was to restore heritage buildings while training local craftsperson about the concepts and techniques of conservation. The project employed "participatory process" by integrating community voices through community meetings as well as by directly employing local people from all quarters of Lomanthang. The project employees were encouraged to learn from the trainee craftsperson as well as from other professional staff. On the other hand, as a social gesture, the project staff also provided assistance to any local organization or resident if the needed any advice or assistance on the matters of their buildings or other aspects of built environment. This included providing some design assistance to local school, providing technical support to local organizations. Many of the professional staff of the project had become seasonal resident of the place and therefore had in many ways become friends with many local people. Be there a need of medical assistance or any other 
household matters requiring some technical assistance, the local people would not hesitate to ask any of the project personnel for help. There would also be occasional picnics and parties for socialization among the team and local residents. Local people working in the project had also occasionally taken part in some events under the banner or identity of the project team. Hence, the project, over the years, had become a part of the community. Such an intimacy had made the interactions among the project participants' easy, thus encouraging dialogues on decision-making process on various matters of on-site works. However there were some people who would not generally agree with the project plans and would voice their concerns at the community meetings. Yet, the plans espoused by project staff would prevail and get necessary support towards implementation. When the author joined the project team, he adapted himself to the overall strategies that were already established in previous years. Later on, in an extension of the project to a nearby village, the author got an opportunity to test some personal thoughts of participatory process from the initial set up of the particular work.

I was given responsibility for initiating a conservation work in a small Gompa (Buddhist temple) in Lo-Gekar, Upper Mustang in Nepal. The Gompa belongs to a small village near by and there was a care taker monk who used to live in the Gompa premises. I spread the word around informing the villagers of some possibility, a few months before the scheduled start date of the project. Out of their curiosity, a group of people from this village even visited Lomanthang where the first project was still in progress. This visit informed them of a typical process followed by our project team, which I found afterwards that the visiting villagers had almost firmly imprinted in their mind that I could not really undertake a participatory process as I had originally thought. I wanted to see the local villagers actively participating in the discussions to set up project goals and processes, which they did but somehow they were cautious not to confront with me. Any way, with the help of the care taker of Lo Gekar Gompa, we have had a preliminary village meeting. It was relatively well attended meeting and I tried to initiate conversations among themselves on what needs to be done and who will participate. By that time, since they had already seen Gompas in other villages restored, they obviously proposed to restore their Gompa too. Though I was aware of the fact that it was not really a complete self-determination on their part, I was satisfied with the process as they looked enthusiastic about the fact that they were been asked for advice. Every phase and day of the work was discussed before actually doing the work. I was delighted that they actually had some better ideas than what I had initially thought for myself. I lived in a small room in the temple premises and had my regular meals with some resident carpenters. The project was launched on an auspicious day with some rituals performed as suggested by the monk to get permission and to apologize for any mistakes during our intervention that might hurt the spirits living on the Gompa. The project progressed as a mutual learning process in a friendly manner. However later I realized that there was a hidden negotiation between me and my local colleagues. No matter how much I would democratize the process of decision making, there would always be a bottom line as to what could or should be done to the building - which was governed by my professional ethics. However, it was not that I was imposing my professional ethics on to them, rather it was their what I now call 'overconsciousness' that led them to ensure that they don't deviate from what I expect to happen (based on what they saw in our works in Lomanthang). Well, it was probably a good achievement for a conservation architect, but I knew that there were some differences in the way we do 'things' and the way the local people would do 'things' in our absences. On the other hand as I look back on how much we influenced the local people on matters of conservation of historic and cultural heritage, it was evident that they would not exactly be following the norms and notions that we would have expected them to follow. At many heritage sites including the ones we worked, the local community follows its own way of dealing with the heritage once the formal conservation project is over. Then, what is the outcome of the participatory process? Is it a 
negotiation between a project and local people while the project is active? Is it just a way to make people agree on what we - the professionals, would like to do? In other words, is it a long way of justifying our professional agenda? My experiences gradually have led me to question my own participatory efforts.

\section{Emerging issues and the notion of participation}

Sanoff (2000) recognizes that the idea of participation has existed well before it was institutionalized in the 1950s and 60s mostly during "the thrid world community development movement(s)." Participatory approaches in conservation and revitalization have been encouraged by various institutions and documents. However, often such notion of participation has not adequately recognized the local people's aspirations and everyday life. This has led to arguments for acknowledging local inhabitants and changing contexts (Chapagain, 2007). The Department of Archaeology in Nepal, which is the primary agency responsible for heritage conservation in Nepal, receives strong recommendations from UNESCO to stop local people from making modern changes to their residences in the vicinity of World Heritage Sites in Kathmandu. UNESCO's strong recommendations have even threatened to take the Kathmandu valley out from the World Heritage Sites list. Criticizing UNESCO's insensitivity towards the issues of local residents around the world heritage sites in Kathmandu, Sobha Shrestha (2002) argues for the need of increased awareness among locals and the Nepali government rather than being obliged to follow UNESCO's recommendations just because the historic urban cores of Kathmandu valley are inscribed in the UNESCO's World Heritage list. Underlying such argument is the mismatch of local aspirations for better living and the universally adopted notion of authenticity in historic cities and practice of conservation. The next door neighbor, India, had experienced similar concerns about the international norms of conservation, which has given rise to the case for an Indian Charter of Conservation (Menon, 2003). Professor Sudarshan Raj Tiwari (1997) cautions that the lapse of civic acknowledgement causes the failure of conservation movement in Nepal and elsewhere in the world, and therefore urban conservation in living heritage sites like the Kathmandu valley needs to raise civic awareness and civil participation. If the strength of conservation lies in its inclination towards local, tradition and history, then its methodological strength can not be anything other than the participatory approach.

Gardner and Lewis (1996), referring to Adnan et. al (1992) point out that the participatory projects can be seen in three broad categories:

1. Participation as a way to inform people about the project and get their feedback.

2. Participation as people's involvement in various capacities, but at the out-set the project is already conceived and planned outside of the community. Here, the participation could be a paid labor, a supervising role, a counter part local partner or a future maintenance or carry on role to what is given by the project.

3. Participation in its true sense that the project is conceived by the people and they initiate the project themselves from the beginning to end.

Similar to these three broad aims of participation, Arnstein (1969'1; republished in Cornwall, 2011) visualizes a " ladder of citizen participation". Arnstein's "ladder" consists of eight rungs in ascending order (moving from the bottom towards top): i) manipulation, and ii) therapy as "Nonparticipation”; iii) informing, iv) consultation, v) placation as "Tokenism", and vi) partnership, vii) delegated power, viii) citizen control as "Citizen Power". Ernstein recognizes that the idea is not limited in such discrete categories, but yet the rungs of the ladder helps us situate the implications of any participatory approach in the spectrum of "nonparticipation" (even if it is claimed as participation), to "tokenism" (is it truly participatory?) and "citizen power" (the ultimate power shift). In other sense, stages under "non-participation" imply that the community is being unidirectionally manipulated

${ }^{1}$ Originally published in 1969 in the Journal of the American Institute of Planners, 35(4), July 1969, pp. 216-24 
or prescribed solutions by the experts (having power of the projects), and hence there is no participation as such. The stages at the "tokenism" do rather lipservice or limited participation, hence they serve as token at best. The true participatory stages as in the "citizen power" category would imply that the decision making power is within the people is hard to achieve, yet it can be achieved to some extent based upon the negotiation between the project and the people.

My own effort of adopting participatory approach discussed above was sometimes close to "tokenism" in Ernstein's terms, and often they were the second type of the participatory process as identified by Gardner and Lewis (1996). At times, when my local colleagues would come up with some ideas that I thought were not appropriate from a conservationist point of view (or from the mission of our project), I would subtly take the matter into discussion with them. Instead of directing them on how to do things, I used a collaborative exploratory approach through which at the end of the day, we would have an agreement on what I never explicitly said before but with which the conservation goals of the project could be achieved. At the time, that was a fair participatory process for me, and I felt very proud of testing a process which I felt was more successful than our previous years in other sites. However, I also realized that there was a certain degree of participation on local colleagues part, that they were participating on the projects' agenda without confronting it because that would be their best bet given the resources they could avail from the given project. It is seen in some other sites that once such projects achieve their stated mission goals and leave the site, the local responsible communities to resort to activities that they would think fit best for the site.

In attempting to pursue participatory approach, one must also keep in mind the "dynamics under which knowledge is shared or hidden in the course of negotiations between 'project planners' and clients” (Novellino, 2003) and that a participatory approach needs an intensive preparation on the professionals' part because " $(\mathrm{t})$ he conditions under which people may decide to 'disclose' their 'knowledge', and make their needs explicit, are very difficult to create" (Novellino, 2003). Therefore, participatory process is more than just having the community participate in any given mission of conservation. Instead, participatory process should seek to contextualize the conservation approaches in to the specific local contexts and beging the conservation and negotiation at the conception stage of a project. At fundamental level, professionals must keep in mind that the professionals are just one of the many groups interested in a given built environment. In this regard, it may be helpful to explore some theoretical frameworks that may help us move beyond our conventional concept of participatory process.

\section{Towards a theoretical framework}

Literatures in other disciplines including anthropology may offer various ways we can frame our approach. Responding to some of the power relationship between professionals and local community, a few theoretical concepts are discussed here in order to wake our professional mindset. Before asking 'how could we get people participate in our efforts', we should ask ourselves about our own 'taken for granted' positions. From our individual cultural background and more importantly from our educational and institutional influence, conservation professionals approach a heritage site from a pre-conceived and often predictable set of values and needs. Such preconceived "knowledge" or "expertise" precludes us from acknolwedging the local community's values, beliefs, desires and needs. While we recognize that their participation is important, we do not care to ask about modes of participation and ultimate goals to be achieved - because those are already inscribed on the project document. Hence, a starting point for a participatory process should be acknowledging each other's positions - regardless of differences; in other words - situating ourselves.

Donna Haraway (1990) uses the notion of "situated knowledges" to indicate how we learn from our given position in a context. The concept to draw from the notion of the "situated knowledges" is to 
realize that what we know is only a perspective from where we are situated. Though her context and scope of discussion is different, we may borrow the notion to think about how a conservation or design professional may pursue a project. Another useful concept of situating our position is the notion of situated learning (Lave and Wenger, 1991) The idea of situated learning is to view the learning process as a participatory process where the learners and teachers both negotiate certain form of knowledge and participate in the project of transmitting that knowledge as appropriate in the particular context. This notion underscores that knowledge is not an abstracted absolute truth, but something that is generated and transmitted as per the context of the setting in which the learning process occurs. I think the practice of urban conservation can better be viewed in the same line of thought, that the values and needs of conservation are not something the professional institution can figure out by itself, but it is a project that both the professional and the inhabitant community need to mutually explore and decide. The core of such an approach is to ensure that all stakeholders participate in the process of exploration, decision making and intervention.

Hence, a participatory process should incorporate the professional's position as a subjective element in the process, and not the objective truth and the ultimate solution to our urban problem. Situating professionals in the project context allows the participation to be open and inclusive - to receive ideas from and to interact with the local population regarding what is important and what needs to be done. It is often easy to espouse and advocate for someone else, but it is challenging to position ourselves into other's territory. This is the quest of participation for the professionals. However, such efforts of situating one's self and negotiating the position with others will rarely be a neutral process. There is always some influence that the professionals exert on local community and vice versa. All of us are a cultural being in many aspects. The conservation professionals are a unique cultural being shaped by some educational and institutional schools of thought. It is only natural that such cultural imprints will always influence how professionals view the world and behave to conserve it. The only way to get out of this professional web in order to gather perspectives from other cultural groups including any local community is to recognize one's own bias first. Any attempt of seeing through other's perspective will be meaningful only by explicitly recognizing one's own perspectives as opposed to suppressing. This is both theoretical and methodological issue. The concepts of 'selfreflexivity' as well as 'auto-ethnography' may help us incorporate some of those theoretical and methodological tools into conservation practice.

The issue of auto-ethnography or self-reflexivity has emerged from some debates in anthropology regarding 'who writes about whom' and 'writing about the self or positioning one's self in the ethnography' (Reed-Danahay, 1997). The debate takes place in the historical development and revision of anthropological field work methods that have originated from the practice of an outsider writing about the 'other', to recent practices of 'writing about self and situating self in the writing'. In a quest to make anthropology objective science about unknown people and culture, the early debates in anthropology were focused on creating objective knowledge which would be possible by distancing oneself from the other. As the 'objectivity' of such knowledge was questioned, the debate then shifted towards 'to what extent anthropological field work is objective or subjective'. An implication of such debate was to recognize an anthropologist as a subjective researcher and that his/her own biases influence the field work and writing about the other culture. Even when someone is writing about their own culture or community, anthropological discussions raised concerns about the individual biases that might have played in the narration of one's own community due to one's formal training and so on. Hence, no matter who writes about whom, it is argued that anthropological writing does not create an objective knowledge but only a partial objective/subjective knowledge. Since participatory processes in conservation intend to draw from the professionals' interaction with host communities, it can be perceived as similar to the work of an anthropologist/ethnographer, and therefore the 
notion of self-reflexivity and auto-ethnography becomes helpful to conservation professionals as well. Similarly, the relevance of auto-ethnographic or self-reflexive approach to participatory conservation process is that the professionals or researchers should recognize where they come from while observing heritage and interpreting what the needs for conservation. In the context of Nepal, this self-reflection must make professionals and researchers aware of their training in a nontraditional (western) school of thoughts where as the heritage sites are products of different traditional communities, that today exist amidst the dynamics of traditional and contemporary contexts. The notion of heritage and conservation may need to be contextualized through the various layers of culture and contemporary needs, which may render the notion of conservation different than what the professionals are taught in their schools. Hence, starting with recognition of one's own position allows us to appreciate and respond to alternate positions that are equally important in heritage sites and the conservation process.

\section{Conclusion: Situating professionals in the process of participation}

Often conservation institutions and professionals have an underlying agenda that the public needs to be made aware of the values of heritage and that they should be encouraged to seek ways to conserve their heritage. However, it is important to recognize that the institutions and professionals represent certain school of thought which is just one of the many ways we could view, value and appreciate history, culture and built environment. Therefore I have suggested to make the institutions and professionals aware of their pre-conceived assumptions and subjective judgment on the matters of culture and built environment. This discussion is a call for professionals and institutions to take a step back from their professional ideology and preconceived notion of heritage and conservation. With an open mindset, one can approach and interact with the local community in order to build a logical base on which a proper conservation plan could be prepared. If a community is the owner and care taker of a built heritage, it is important that they are recognized early on and are involved duly in the entire process. Of course, a community is always diverse and there may not be consensus on any single issue - but the project must start with recognizing this fact. More importantly, the conservation professional community is just one of those diverse interest groups seeking to voice their opinion rather than to impose their opinion. The argument here is not to swing the approach from experts domain to local community domain, but rather to allow a fair interaction and negotiation between the different interest groups. Drawing some theoretical and methodological approaches from anthropology may be helpful to articulate different subjective and 'taken for granted' assumptions. A key implication of such approach is that it helps to situate the professionals in the process of participation in the conservation process. A participatory approach entails inclusion of such diversity while contributing for care and continuity of heritage. The physical aspects of built environment alone does not make its complete story,

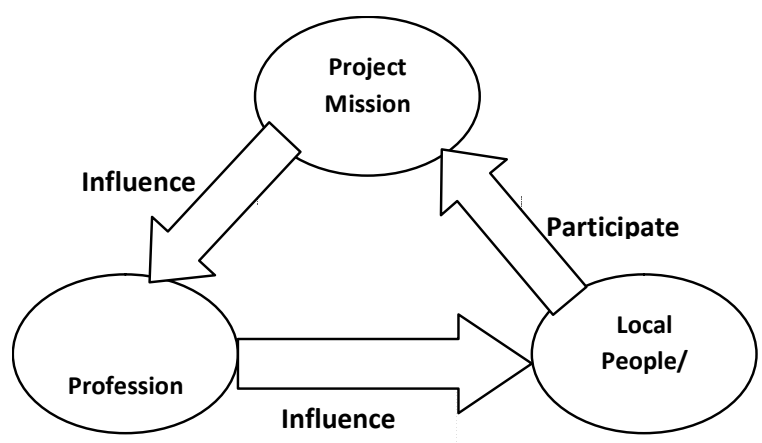

Fig.1. A conventional process of participation

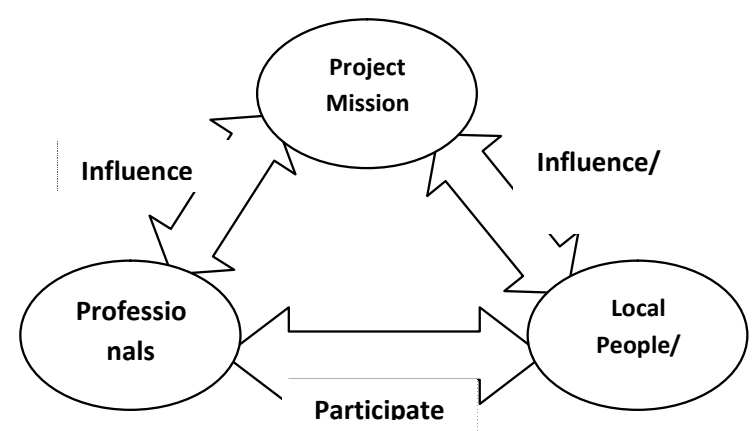

Fig.2. Towards a re-conceptualization of participation 
it is with incorporation of diverse wakes of lives and culture that the built environment gets life. This is possible only if all the stakeholders come onboard the conservation process with their own authority and this is possible only if the professionals join others in mutually recognizing each others. Situating the professionals themselves in the process of participation should be the first step towards the framework of participatory conservation approach. The following diagram is an attempt to summarizes the argument made in this paper, which is open for discussion.

\section{References}

[1] Arnstein, Sherry R.(2011). The ladder of citizen participation. In Andrea Cornwall (Ed.), The Participation Reader (pp. 3 - 18).New York, London: Zed Books

[2] Chapagain, N. K. (2007). Revisiting conservation charters in context of Lomanthang, Nepal: need to acknowledge local inhabitants and changing contexts. City \& Time 3 (2): 5. [online] URL: http://www.ct.cecibr.org

[3] Cornwall, A. (2011). The participation reader. London: Zed Books.

[4] Lave, J., \& Wenger, E. (1991). Situated learning: Legitimate peripheral participation. Learning in doing. Cambridge [England]: Cambridge University Press.

[5] Menon, A. G. K. (2003). The case for an Indian charter. Seminar Volume 530. Retrieved $22^{\text {nd }}$ December 2008, from http://www.india-seminar.com/cd8899/ cd_frame8899.html

[6] Gardner, K., \& Lewis, D. J. (1996). Anthropology, development, and the post-modern challenge. London; Sterling, Va.: Pluto Press.
[7] Haaland, A. (1982). Bhaktapur, a town changing: Process influenced by Bhaktapur Development Project. Kathmandu, Nepal: Available from Bhaktapur Development Project.

[8] Haraway, D. J. (1990). Situated knowledges: The science question in feminism and the privilege of partial perspective. Simians, cyborgs, and women: The reinvention of nature (pp. 183). New York: Routledge.

[9] Marcus, G. E. (1998). Ethnography through thick and thin. Princeton, N.J.: Princeton University Press.

[10] Novellino, D. (2003). From seduction to miscommunication: the confession and presentation of local knowledge in 'participatory development'. In J. Pottier, A. Bicker and P. Sillitoe (Eds.) Negotiating Local Knowledge: power and identity in development. London; Sterling, Va.: Pluto Press.

[11] Parajuli, Y. K. (1992). Lessons of Bhaktapur. HIMAL, $5,11$.

[12] Reed-Danahay, D. (1997). Introduction. In D. ReedDanahay (Ed.), Auto/Ethnography, rewriting the self and the social (pp. 1 - 17). Oxford, New York: Berg.

[13] Sanoff, H. (2000). Community participation methods in design and planning. New York: Wiley.

[14] Shrestha, S. (2002). Sampada Samrakshan, Samlagna Sanstha ra dekhiyeka samsya haru (in Nepali). Ancient Nepal, Number 149, March 2002.

[15] Tiwari, S.R. (1997). Conservation - the issue of civic acknowledgement. Unpublished paper, presented in Conservation Workshop organized by B.P. Koirala Nepal-India Foundation, May 17, 1997, Kathmandu. Retrieved 9th November 2007, from http:// www.kailashkut.com 